\title{
Effects of Electrolyte Concentration, Temperature, Flow Velocity and Current Density on Zn Deposit Morphology
}

\author{
Aleksandra Gavrilović-Wohlmuther ${ }^{1}$, Andreas Laskos ${ }^{1}$, Christian Zelger ${ }^{1,2}$, Bernhard Gollas ${ }^{1,2}$ and Adam \\ Harding Whitehead ${ }^{3}$ \\ 1. CEST_Centre of Electrochemical Surface Technology GmbH, Wiener Neustadt 2700, Austria \\ 2. Institute for Chemistry and Technology of Materials, Graz University of Technology, Graz 8010, Austria \\ 3. Cellstrom GmbH, Wiener Neudorf 2355, Austria
}

Received: September 02, 2015 / Accepted: September 18, 2015 / Published: November 30, 2015.

\begin{abstract}
The most critical disadvantages of the $\mathrm{Zn}$-air flow battery system are corrosion of the zinc, which appears as a high self-discharge current density and a short cycle life due to the non-uniform, dendritic, zinc electrodeposition that can lead to internal short-circuit. In our efforts to find a dendrite-free $\mathrm{Zn}$ electrodeposition which can be utilized in the $\mathrm{Zn}$-air flow battery, the surface morphology of the electrolytic $\mathrm{Zn}$ deposits on a polished polymer carbon composite anode in alkaline, additive-free solutions was studied. Experiments were carried out with $0.1 \mathrm{M}, 0.2 \mathrm{M}$ and $0.5 \mathrm{M}$ zincate concentrations in $8 \mathrm{M} \mathrm{KOH}$. The effects of different working conditions such as: elevated temperatures, different current densities and different flow velocities, on current efficiency and dendrite formation were investigated. Specially designed test flow-cell with a central transparent window was employed. The highest Coulombic efficiencies of $80 \%-93 \%$ were found for $0.5 \mathrm{M} \mathrm{ZnO}$ in $8 \mathrm{M} \mathrm{KOH}$, at increased temperatures $\left(50-70{ }^{\circ} \mathrm{C}\right)$, current densities of up to $100 \mathrm{~mA} \cdot \mathrm{cm}^{-2}$ and linear electrolyte flow velocities higher than $6.7 \mathrm{~cm} \cdot \mathrm{s}^{-1}$.
\end{abstract}

Key words: Dendrite, electrochemistry, flow battery, zinc, zinc morphology.

\section{Introduction}

With the rapidly increasing demand for efficient use of renewable, clean, but often intermittent and difficult to predict sources of energy, such as solar power and wind, it is necessary to develop sustainable and low cost energy storage systems. Redox flow batteries with their ability to store relatively cheaply large amounts of electrical energy, promise to meet these requirements. The very first flow battery was constructed by Charles Renard in 1884. Renard used zinc and chlorine as the reactive elements to power his army airship La France. Further developments were made many years after, by NASA (National Aeronautics and Space

Corresponding author: Aleksandra
Gavrilović-Wohlmuther, Dr., research fields: flow batteries, novel materials for energy conversion and storage, metallic glasses. E-mail: aleksandra.gavrilovic@cest.at.

This work was carried out at CEST GmbH under grants from the POWAIR project supported from the EU (grant number 256759) 2010, FP7 energy call 2010.7.3.1.
Administration) scientist Thaller in 1974. Thaller's redox flow battery was comprised of iron and chromium [1]. Since that time, the design of the redox flow battery systems has evolved as witnessed by review of the numerous papers that have been published over the last four decades [2-15]. And yet, this field is still in its infancy due to the lack of suitable electrode and electrolyte materials, together with difficulties in mastering the interfaces between them. Most redox flow battery systems require expensive ion-exchange membranes to separate the two electrolytes. However, the so-called single electrolyte flow battery systems avoid the need for a membrane. One of the most promising candidates in this field is the rechargeable $\mathrm{Zn}$-air flow battery [16]. Zinc is an attractive material for secondary alkaline batteries due to the high energy density, low equilibrium potential, high hydrogen overpotential, low cost, high abundance 
and environmental friendliness [17, 18]. Upon charging, zincate ions are electrochemically reduced to metallic zinc. Zn deposits can grow with different morphologies, described as: filamentous mossy, spongy and dendritic [19]. The most critical disadvantages of the $\mathrm{Zn}$-air flow battery system are corrosion of the zinc, which appears as a high self-discharge current density, and a short cycle life due to the non-uniform, dendritic, zinc electrode position that can lead to internal short-circuit [20-22]. Another problem to address is the hydrogen evolution, which significantly affects the morphology of deposits. In turn, the deposit morphology has an influence on the Coulombic efficiency of the charge/discharge cycle. At the beginning of charging, depending on the type of electrode used, the active surface area for zinc deposition can be small, thus the release of hydrogen bubbles can cause dendrite formation and potential oscillations in the cell [23]. Many attempts have been made in order to improve the appearance and physico-chemical properties of the deposits by introducing various organic and inorganic additives [24-27]. However, the effect of electrolyte concentration on the current efficiency of the alkaline zinc processes together with temperature and especially electrolyte flow velocity on the resultant morphological properties, to the best of our knowledge have not been reported quantitatively in the literature [28-31]. Therefore, this work is focused on the morphology of zinc electrodeposited from different additive-free alkaline zincate solutions which can be utilized in the rechargeable zinc-air flow batteries. The effects of different working conditions, such as elevated temperatures, different current densities and different electrolyte flow rates, on current efficiency and dendrite formation, for specific bath compositions are reported.

\section{Experimental Section}

Prior to the flow cell experiments, Rota-Hull cell (Eco Chemie B.V., Utrecht, Holland) experiments in various $\mathrm{KOH}$, additive-free, zincate solutions on brass cylinder electrodes with a diameter of $6 \mathrm{~mm}$ and an active surface area of $15 \mathrm{~cm}^{2}$, have been carried out. The Rota-Hull cell experiments were performed in order to accelerate screening and to identify the most promising parameter combinations which could be further tested in the flow cell. The counter electrode was a platinized titanium mesh. The electrolyte volume was $700 \mathrm{~mL}$. Zinc was deposited at 25, 30, 50 and $70{ }^{\circ} \mathrm{C}$, rotation rates of 95,191 and $509 \mathrm{rpm}$, which corresponds to the linear flow velocities: 3,6 and $16 \mathrm{~cm} \cdot \mathrm{s}^{-1}$, respectively and $\mathrm{ZnO}$ concentrations of $0.1,0.2$ and $0.5 \mathrm{M}$. In cases where two different $\mathrm{Zn}$ deposit morphologies were observed, there was an intermediate zone of mixed morphology. From a known correlation between primary current density and position on the electrode, the first occurrence of dendrites in an otherwise mossy deposit was used to determine the transition current density.

For the investigation of $\mathrm{Zn}$ plating and stripping in flowing electrolyte, a special test rig was constructed. The test rig was equipped with: two flow-meters for different flow ranges (Bio-Tech 97478625 and Bio-Tech 97478321, Germany), two differential pressure sensors (Motorola- Freescale MPX-2010 DP, United Kingdom), an electrolyte heater made from stainless steel (Galvatek ROTKAPPE FC 27, Finland), a PT100 temperature sensor (Galvatek SOPT2 F2000T0, Finland) and an AC magnetically- coupled centrifugal pump (Sondermann RM-PP-EKKK-2/20-30(30)-60-3-G, Germany). An IM6 Potentiostat-Galvanostat (ZAHNER-elektrik $\mathrm{GmbH}$, Germany) was used as the power source for the electrochemical test flow half-cell. The test flow cell, for studying the $\mathrm{Zn}$ - half cell of the $\mathrm{Zn}$-air flow battery, was designed by C-Tech Innovation Ltd (Fig. 1). The test flow cell was connected with a $5 \mathrm{~L}$ tank of electrolyte. The electrolytes used for the experiments were concentrated aqueous $\mathrm{KOH}$ solutions (Sigma Aldrich, 99.99\%) containing dissolved ZnO (Sigma Aldrich, 99.99\%). All electrolytes contained $8 \mathrm{M} \mathrm{KOH}$. The $\mathrm{KOH}$ electrolyte was chosen in preference to 
$\mathrm{NaOH}$ due to its high conductivity and faster kinetics for the zinc deposition as well as the oxygen reduction process. The solubility of $\mathrm{ZnO}$ in different $\mathrm{KOH}$ concentrations and the viscosity of these solutions have been previously determined [21]. It was found that, for $\mathrm{KOH}$ concentrations higher than $8 \mathrm{M}$, the viscosity increases sharply. It was also found that, the oxygen solubility decreases with higher alkaline content, which is detrimental to the performance of the air electrode [21]. Based on these findings, the concentrations of dissolved $\mathrm{ZnO}$ were chosen to be: $0.1 \mathrm{M}$, $0.2 \mathrm{M}$ and $0.5 \mathrm{M}$ for three different electrolytes. No additives were used. During the flow cell experiments, metallic zinc was deposited on a polished polymer carbon composite, ElectroPhen ${ }^{\circledR}$ (BAC2 Limited, Romsey, United Kingdom) with $10 \mathrm{~cm}^{2}$ geometric surface area, serving as current collector. The second electrode, aligned parallel to the first and of similar area, was a Zn plate (Advent Research Materials Ltd, United Kingdom, purity 99.5\%). The initial gap between both electrodes was $5 \mathrm{~mm}$. During cycling, it was possible to visually inspect the morphology of the $\mathrm{Zn}$ deposits, as well as the evolution of hydrogen and oxygen at the electrodes through a central transparent window of the test flow cell (Fig. 1). Scanning electron microscopy (SEM, XL30 Field Emission ESEM, with High-Brightness Field Emission Gun-FEG, Field Electron and Ion Co., Nederland) was used to study the morphology of the $\mathrm{Zn}$ electrode after disassembling the cell and subsequent rinsing with deionized water and drying.

Flow cell experiments were carried out at 25, 30, 50 and $70{ }^{\circ} \mathrm{C}$, in combination with current densities of 10 , 50 and $100 \mathrm{~mA} \cdot \mathrm{cm}^{-2}$ as well as electrolyte flow rates of $0.2,0.5$ and $0.8 \mathrm{~L} \cdot \mathrm{min}^{-1}$. The latter correspond to linear flow velocities of $6.7 \mathrm{~cm} \cdot \mathrm{s}^{-1}, 16.7 \mathrm{~cm} \cdot \mathrm{s}^{-1}$ and $26.7 \mathrm{~cm} \cdot \mathrm{s}^{-1}$, respectively (calculated for the interelectrode gap prior to deposition). Each cycling experiment consisted of 24 cycles. Each cycle consisted of 30 min plating followed by stripping until the cell potential difference reached $600 \mathrm{mV}$. The next plating step commenced

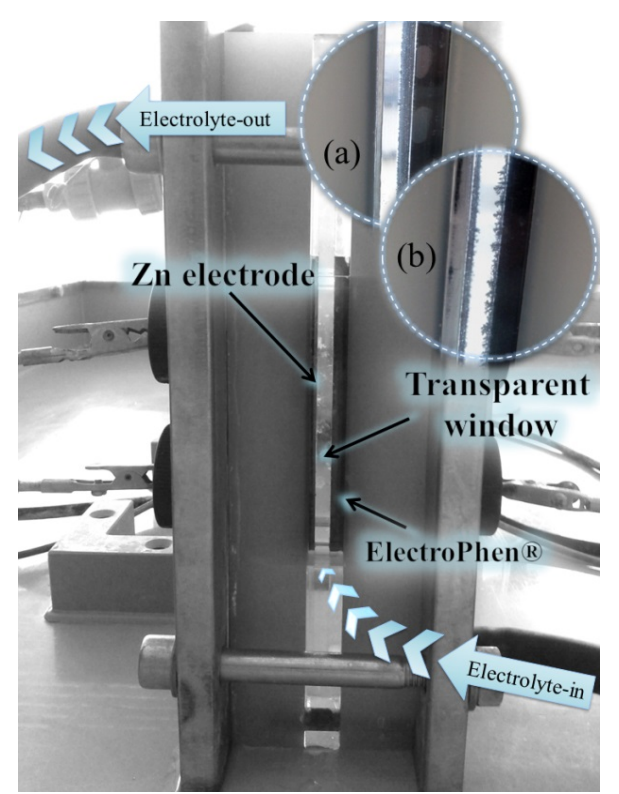

Fig. 1 Two-electrode, electrochemical test flow half-cell. The transparent window in the middle of the test flow cell (magnified as an example in the right corner- circles, with: (a) electrodeposited compact and dendrite-free $\mathrm{Zn}$ layer and (b) electrodeposited dendritic Zn layer on BAC2 electrode), provides opportunity for an in-situ visual study of the surface morphology of the $\mathrm{Zn}$ deposits. In-situ monitoring and control of the electrolyte flow speed, pressure difference and electrolyte temperature is possible.

immediately following the stripping step. Cyclic voltammograms were recorded using (VoltaLab PGZ301 Radiometer Analytical), on a BAC2 electrode, in the voltage range $-0.1 \mathrm{~V}$ to $-2.5 \mathrm{~V}$ vs. $\mathrm{Hg} / \mathrm{HgO}$ of additive free $0.1 \mathrm{M}, 0.2 \mathrm{M}$ and $0.5 \mathrm{M} \mathrm{ZnO}$ in $8 \mathrm{M} \mathrm{KOH}$ at room temperature and at $50{ }^{\circ} \mathrm{C}$, respectively. The sweep rate was $50 \mathrm{mV} \cdot \mathrm{s}^{-1}$ and a Pt plate with $10 \mathrm{~cm}^{2}$ geometric surface area was used as counter electrode.

For investigation of the grey residue, found at the bottom of the electrolyte tank, an X-Pert powder diffractometer (PAN-alytical, Netherlands) with $\mathrm{Cu}-\mathrm{K} \alpha$ radiation in Bragg-Brentano geometry, at $40 \mathrm{kV}$ and $30 \mathrm{~mA}$ was used.

\section{Results and Discussion}

\subsection{Cyclic Voltammetry}

In each curve in Fig. 2a, there is a well-defined reduction peak for zincate, at $-1.69 \mathrm{~V}(0.1 \mathrm{M}),-1.70 \mathrm{~V}$ $(0.2 \mathrm{M})$ and $-1.85(0.5 \mathrm{M})$ in the cathodic scan and an 


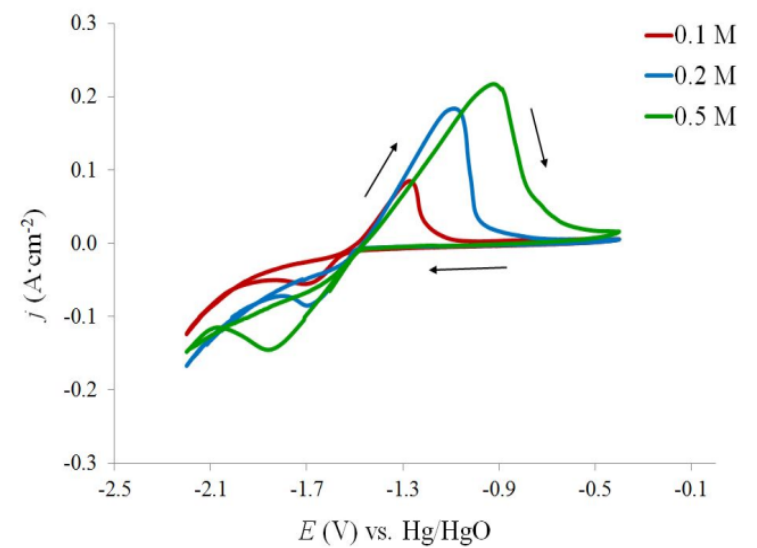

(a)

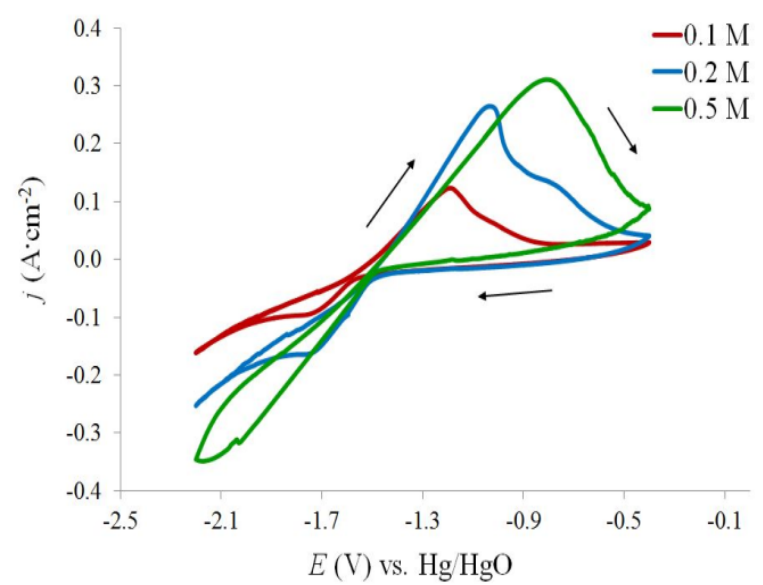

(b)

Fig. 2 Cyclic voltammograms in stagnant $0.1 \mathrm{M}, 0.2 \mathrm{M}$ and 0.5 M potassium zincate solutions at BAC2 electrode at: (a) room temperature and (b) $50{ }^{\circ} \mathrm{C}$. Between experiments, electrolytes were purged with air. The initial sweep was in cathodic direction with a starting potential of ca. $-1 \mathrm{~V}$ vs. $\mathrm{Hg} / \mathrm{HgO}$. The sweep rate was $50 \mathrm{mV} \cdot \mathrm{s}^{-1}$ and $\mathrm{Hg} / \mathrm{HgO}$ was used as reference electrode.

oxidation peak at $-1.27 \mathrm{~V}(0.1 \mathrm{M}),-1.10 \mathrm{~V}(0.2 \mathrm{M})$ and at $-0.90 \mathrm{~V}(0.5 \mathrm{M})$ in the anodic scan, indicating dissolution of the bulk zinc layer. A shoulder in the peak for Zn stripping is observed in Fig. 2b. Such shoulders or double peaks in anodic stripping presumably appear due to the fact that the zincate solubility limit was temporarily exceeded in the diffusion layer. Somewhat higher current densities for reduction and oxidation peaks in Fig. 2b, in comparison to the corresponding cyclic voltammograms in Fig. 2a, indicate higher diffusion rates at $50{ }^{\circ} \mathrm{C}$ due to the decrease in electrolyte viscosity and therefore higher migration.

\subsection{Rota-Hull Cell Experiments}

The Rota-Hull cell study is used for the pre-screening of $\mathrm{Zn}$ deposit morphology over a wide range of current densities, for different hydrodynamic conditions. Zinc was deposited for $30 \mathrm{~min}$ and a mean current density of $50 \mathrm{~mA} \cdot \mathrm{cm}^{-2}$. The Rota-Hull cell zinc deposits from $8 \mathrm{M}$ $\mathrm{KOH}$ containing $0.5 \mathrm{M} \mathrm{ZnO}$ showed a transition from the filamentous mossy zinc morphology at lower current densities to the dendritic zinc morphology at the higher current densities. The current density of the transition zone shifted to higher current densities with increasing linear flow velocities, Fig. 3.

As an example, the SEM micrograph of the dendritic $\mathrm{Zn}$ deposit obtained at room temperature, at $50 \mathrm{~mA} \cdot \mathrm{cm}^{-2}$ current density and with $3 \mathrm{~cm} \cdot \mathrm{s}^{-1}$ linear flow velocity is shown in Fig. 4. Higher operating temperatures in the rechargeable zinc-air flow battery should increase the electrolyte conductivity and salt solubility and also the kinetics of the air electrode. Therefore, it was of particular interest to examine the effect of electrolyte temperature on the $\mathrm{Zn}$ plating and dissolution under these conditions. By increasing the electrolyte temperature to $70{ }^{\circ} \mathrm{C}$, at all rotation rates/linear flow velocities and current densities of $j \leq 50 \mathrm{~mA} \cdot \mathrm{cm}^{-2}$, dark-grey mossy zinc deposits were obtained. These

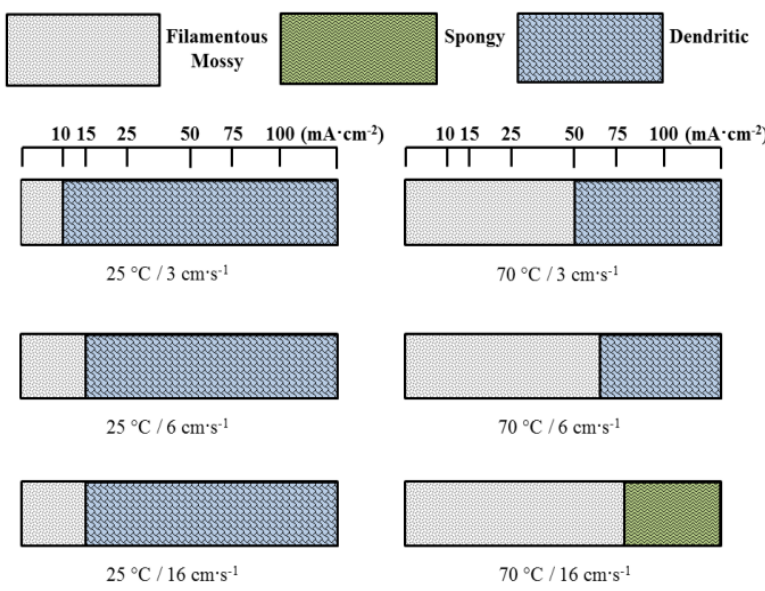

Fig. 3 Morphology pattern of the zinc deposits from Rota-Hull cell experiments at different electrolyte temperatures and various electrolyte flow velocities, in additive-free $8 \mathrm{M} \mathrm{KOH}$ containing $0.5 \mathrm{M} \mathrm{ZnO}$. The deposition time was $30 \mathrm{~min}$ and a mean current density of $50 \mathrm{~mA} \cdot \mathrm{cm}^{-2}$ was applied. 


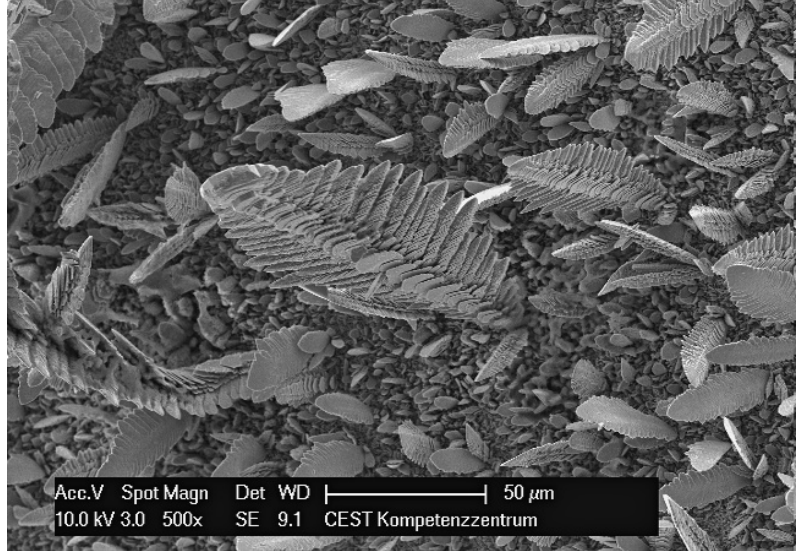

Fig. 4 SEM micrograph of the dendritic $\mathrm{Zn}$ deposit obtained from $0.5 \mathrm{M} \mathrm{ZnO}$ in $8 \mathrm{M} \mathrm{KOH}$ at room temperature, with a linear flow velocity of $3 \mathrm{~cm} \cdot \mathrm{s}^{-1}$ and a current density of $50 \mathrm{~mA} \cdot \mathrm{cm}^{-2}$ on a brass cylinder electrode.

deposits showed a moderate mechanical stability against water rinsing (wash bottle).

The dark-grey colored filamentous mossy deposits obtained from $0.5 \mathrm{M}$ zincate in $8 \mathrm{M} \mathrm{KOH}$ at $70{ }^{\circ} \mathrm{C}$, current density of $50 \mathrm{~mA} \cdot \mathrm{cm}^{-2}$ and linear flow velocity of $6 \mathrm{~cm} \cdot \mathrm{s}^{-1}$ are shown in Fig. 5. At constant temperature and increasing flow velocity of the electrolyte, the transition from the filamentous mossy to the dendritic zinc morphology was shifted to higher current densities.

This can be explained by the increased convection, shifting the limiting current density to higher values. It was also found that, at a constant linear flow velocity and increasing electrolyte temperature, the transition point from filamentous mossy to dendritic zinc morphology was shifted to higher current densities. With increasing temperature, the electrolyte viscosity is decreased, hence the ionic mobility of the zincate ions is increased. The increased mobility of the zincate ions shifts the limiting current density to the higher values. During extended periods of charging and discharging of the secondary zinc-air flow battery, the zincate concentration in the electrolyte varies significantly. Thus, it is important to know for which combinations of parameters (temperature, current density, flow rate) at a given zincate concentration dendrites start to grow.

Based on the results of Rota-Hull cell experiments, electrolytes with $0.1 \mathrm{M} \mathrm{ZnO}$ gave dendritic deposit

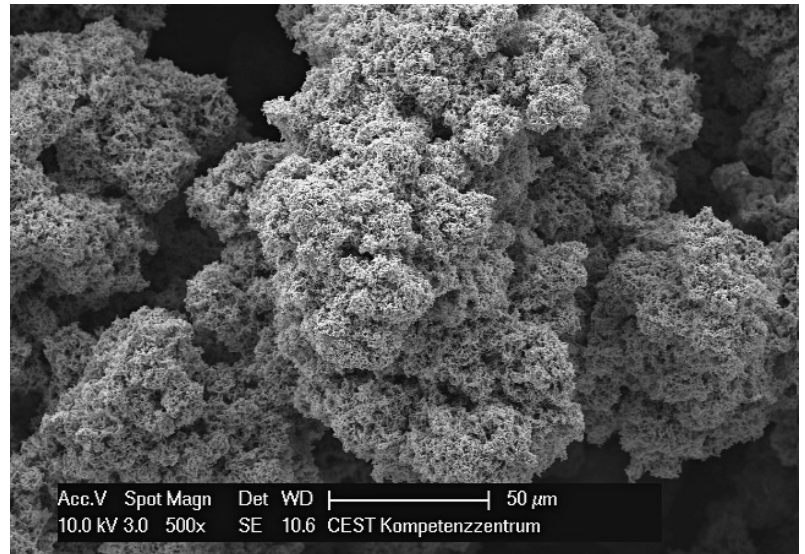

(a)

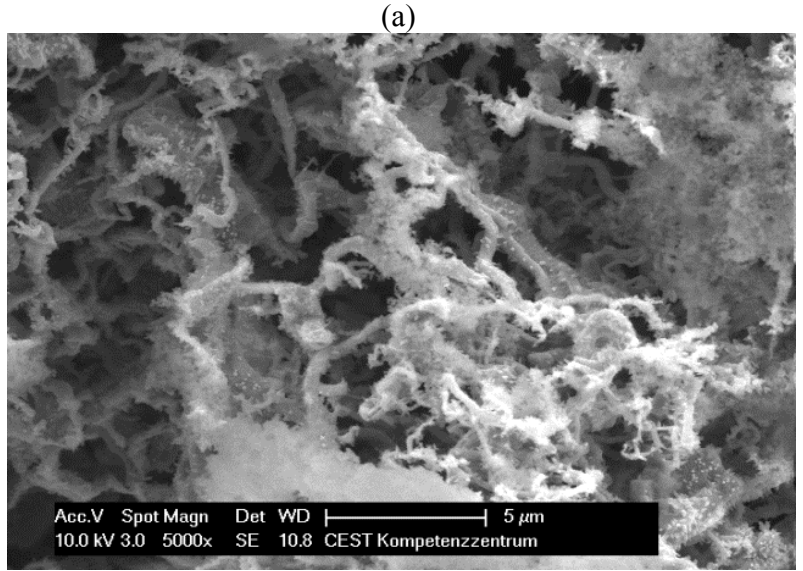

(b)

Fig. 5 (a) SEM micrograph of the filamentous mossy zinc deposits from $0.5 \mathrm{M}$ zincate in $8 \mathrm{M} \mathrm{KOH}$ at $70{ }^{\circ} \mathrm{C}$, at a current density of $50 \mathrm{~mA} \mathrm{~cm}$ and a linear flow velocity of $6 \mathrm{~cm} \cdot \mathrm{s}^{-1}$. (b) Same as for micrograph (a) but at higher magnification.

morphologies at all temperatures, rotation rates and current densities. A small window for spongy deposit morphology was observed only at $70{ }^{\circ} \mathrm{C}$, a flow velocity of $16 \mathrm{~cm} \cdot \mathrm{s}^{-1}$ and current densities lower than $13 \mathrm{~mA} \cdot \mathrm{cm}^{-2}$.

It is well known that growth of different deposit morphologies is a rather complex process. Various kinetic and thermodynamic properties play a role in electrocrystallization $[31,32]$. When zincate is reduced, the hydroxide ion concentration increases at the electrode and affects the reaction. This change in the kinetic and thermodynamic conditions of the zincate reduction reaction results in the initiation of a mossy morphology (Figs. 5a and 5b). Hence, the deposition conditions favoring mossy zinc are higher zincate concentrations, higher temperature and a surface which 
provides a high number of nucleation centers. The formation of the mossy morphology is under activation control in contrast to diffusion controlled dendritic growth.

\subsection{The Flow Cell Experiments}

After the Rota-Hull investigations, flow cell experiments were performed. In each experiment, a $1 \mathrm{~h}$ long deposition/dissolution cycle was repeated twenty-four times. As an example, several voltage vs. time figures ( $\mathrm{Zn}$ plating/stripping under galvanostatic control) for $0.5 \mathrm{M}$ zincate concentrations in $8 \mathrm{M} \mathrm{KOH}$ at various temperatures are shown in Fig. 6. During plating/stripping cycles, a ZAHNER-elektrik Potentiostat's software was programed to limit the maximum stripping voltage to $600 \mathrm{mV}$, thereby protecting the carbon electrode from corrosion. Thus when the stripping potential reached the $600 \mathrm{mV}$, a new plating was immediately unleashed regardless the initially planned length of the stripping cycle. Reader should note that, these results corresponding solely to the measurements of the $\mathrm{Zn}$-half of the $\mathrm{Zn}$-air flow battery, where in the two-electrode, electrochemical test flow system metallic zinc was deposited on a polished polymer carbon composite and in the same time zinc was dissolved at the second electrode ( $\mathrm{Zn}$ plate), aligned parallel to the first one (Fig. 1). It was found that, at $0.5 \mathrm{M} \mathrm{ZnO}$ concentration, the Coulombic efficiency for each set of parameters at room temperature ranges from $64 \%$ to $80 \%$.

Dendrite formation is observed only at the highest current density of $100 \mathrm{~mA} \cdot \mathrm{cm}^{-2}$ in combination with the lowest flow rate of $6.7 \mathrm{~cm} \cdot \mathrm{s}^{-1}$. Such a discrepancy between the results obtained with the Rota-Hull cell (Fig. 3) and with the flow cell (Fig. 7) cannot be simply explained by the theories of mass transfer in various cell geometries. Although the linear flow velocities are in the same range, the transition from laminar to turbulent flow occurs at much lower Reynolds numbers in the Rota-Hull [33] compared to the flow cell experiments [34]. Thus, the different substrate materials in both set-ups as well as the different conditions for the release of hydrogen bubbles from the surfaces due to different electrode geometries are more likely to play decisive role here for the morphology of the $\mathrm{Zn}$ layers.

The electrodeposition in highly alkaline electrolytes produces predominant mossy or spongy zinc deposits. The spongy type deposits (Fig. 8) are mainly formed at higher temperature $\left(T=70{ }^{\circ} \mathrm{C}\right)$ and high current density $\left(j=100 \mathrm{~mA} \cdot \mathrm{cm}^{-2}\right)$. The adherence of the mossy zinc layers is found to be better than that of the spongy type zinc deposits.

The fact that spongy deposits are observed only at higher temperatures is important, because detachment of zinc particles can occur when the sponge type zinc dissolves on discharging. These zinc particles are sparingly soluble in the electrolyte, due to their low corrosion rate in $\mathrm{KOH}$. This is experimentally confirmed. Namely, the detached particles are found at the bottom of the electrolyte tank in the form of a grey residue. The residue was collected, rinsed in deionized water, dried and examined by X-ray diffraction. This qualitative analysis confirmed that the grey powder exclusively consisted of $\mathrm{Zn}$ and $\mathrm{ZnO}$ crystalline phases.

By decreasing the zincate concentration in the electrolyte, the Coulombic efficiency decreased to $49 \%-78 \%$. This decrease of Coulombic efficiency is more pronounced at higher temperatures, which is probably caused by increased reaction rates of hydrogen evolution and of zinc corrosion. The onset of dendrite formation also increased for decreasing zincate concentration. For example, dendrites were observed at $50{ }^{\circ} \mathrm{C}, 50 \mathrm{~mA} \cdot \mathrm{cm}^{-2}$ and maximal flow rates of $26.6 \mathrm{~cm} \cdot \mathrm{s}^{-1}$ at $0.1 \mathrm{M} \mathrm{ZnO}$, while the same conditions with $0.2 \mathrm{M} \mathrm{ZnO}$ gave dendrite-free deposits.

The key findings (limiting conditions for onset of dendrite growth) extracted from this work and corresponding to the flow cell experiments are summarized in Figs. 7 and 9. 
Effects of Electrolyte Concentration, Temperature, Flow Velocity and Current Density on Zn Deposit Morphology

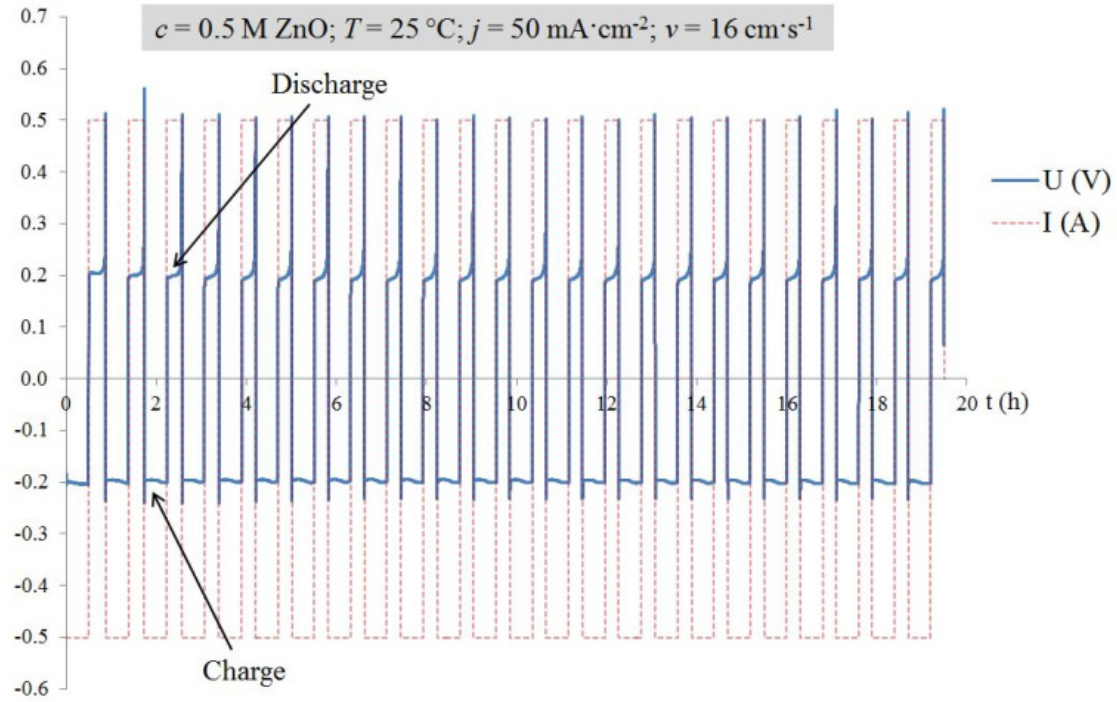

(a)

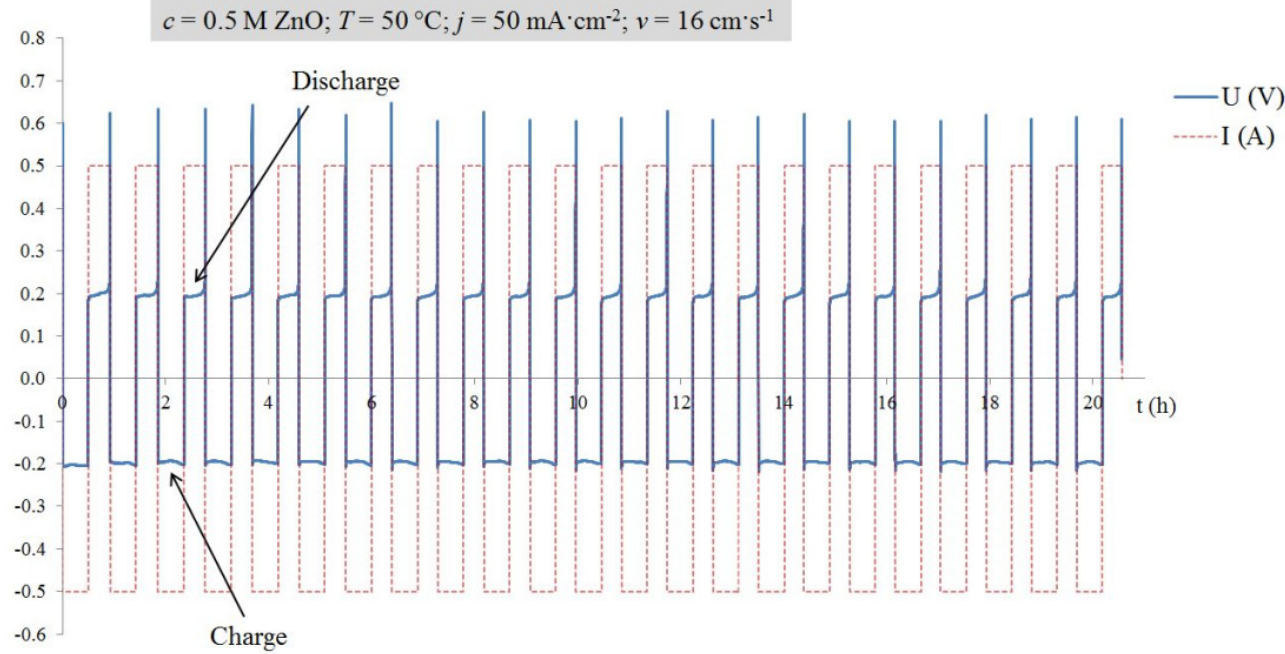

(b)

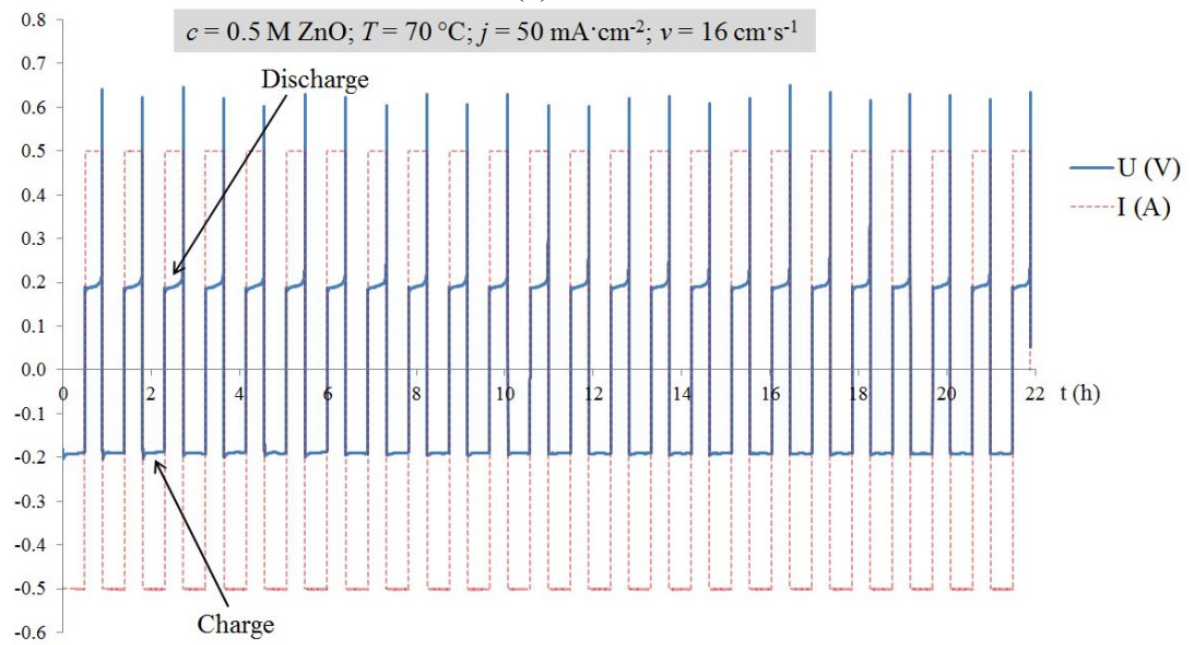

(c)

Fig. $6 c=0.5 \mathrm{M} \mathrm{ZnO}, j=50 \mathrm{~mA} \cdot \mathrm{cm}^{-2}, v=16.7 \mathrm{~cm} \cdot \mathrm{s}^{-1}$. (a) $T=25^{\circ} \mathrm{C}$, (b) $T=50{ }^{\circ} \mathrm{C}$ and (c) $T=70^{\circ} \mathrm{C}$. At the end of each stripping cycle, the voltage rises when there is no more $\mathrm{Zn}$ to strip. 

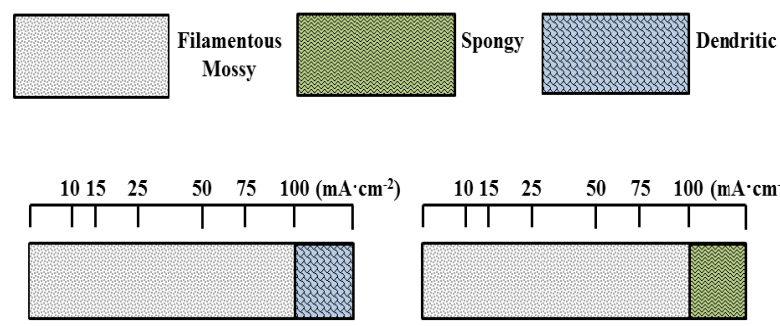

$25^{\circ} \mathrm{C} / 6.7 \mathrm{~cm} \cdot \mathrm{s}^{-1}$

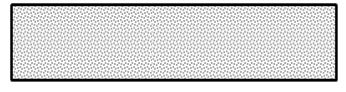

$25^{\circ} \mathrm{C} / 16.7 \mathrm{~cm} \cdot \mathrm{s}^{-1}$

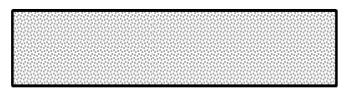

$25^{\circ} \mathrm{C} / 26.7{\mathrm{~cm} \cdot \mathrm{s}^{-1}}^{-1}$

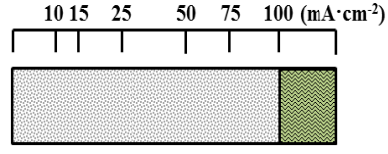

$70^{\circ} \mathrm{C} / 6.7{\mathrm{~cm} \cdot \mathrm{s}^{-1}}^{-1}$

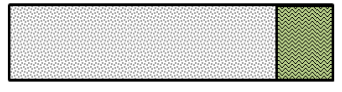

$70{ }^{\circ} \mathrm{C} / 16.7 \mathrm{~cm} \cdot \mathrm{s}^{-1}$

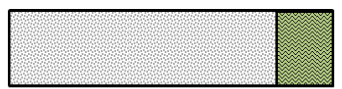

$70{ }^{\circ} \mathrm{C} / 26.7 \mathrm{~cm} \cdot \mathrm{s}^{-1}$

Fig. 7 Morphology of the zinc deposits in flow cell experiments as function of current density at two different electrolyte temperatures and three electrolyte flow velocities, from additive-free $8 \mathrm{M}$ KOH containing $0.5 \mathrm{M} \mathrm{ZnO}$.

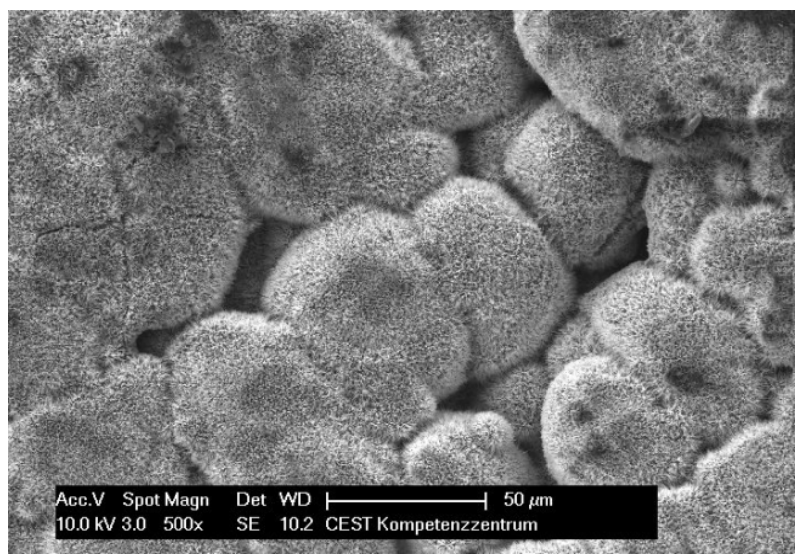

(a)

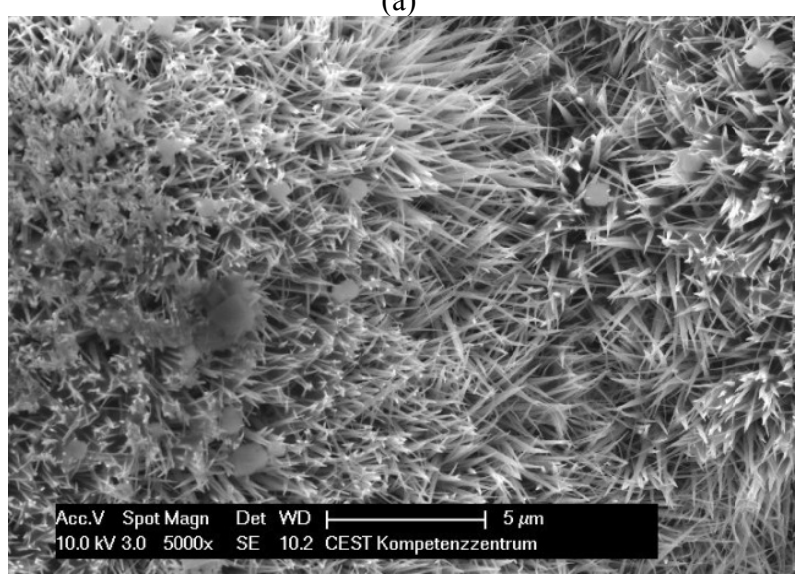

(b)

Fig. 8 (a) SEM micrograph of the spongy zinc deposits from $0.5 \mathrm{M}$ zincate in $8 \mathrm{M} \mathrm{KOH}$ at $70{ }^{\circ} \mathrm{C}$, current density of $100 \mathrm{~mA} \cdot \mathrm{cm}^{-2}$ and linear flow rate of $6.7 \mathrm{~cm} \cdot \mathrm{s}^{-1}$. (b) Same as for micrograph (a) but at higher magnification.

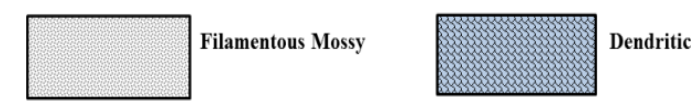

$25^{\circ} \mathrm{C} / 6.7 \mathrm{~cm} \cdot \mathrm{s}^{-1}$

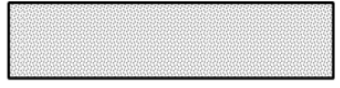

$25^{\circ} \mathrm{C} / 16.7 \mathrm{~cm} \cdot \mathrm{s}^{-1}$

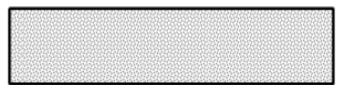

$25^{\circ} \mathrm{C} / 26.7{\mathrm{~cm} \cdot \mathrm{s}^{-1}}^{-1}$

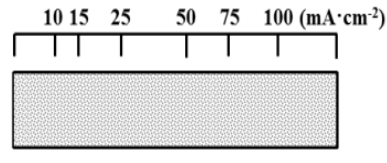

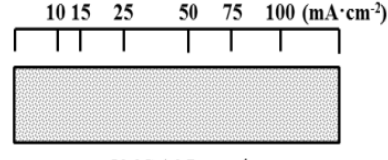

$50{ }^{\circ} \mathrm{C} / 6.7 \mathrm{~cm} \cdot \mathrm{s}^{-1}$

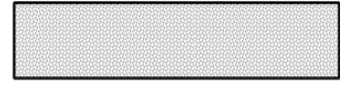

$50{ }^{\circ} \mathrm{C} / 16.7 \mathrm{~cm} \cdot \mathrm{s}^{-1}$

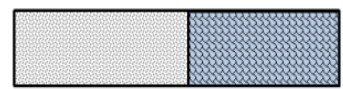

$50^{\circ} \mathrm{C} / 26.7 \mathrm{~cm} \cdot \mathrm{s}^{-1}$
Fig. 9 Morphology of the zinc deposits in flow cell experiments as function of current density at two different electrolyte temperatures and three electrolyte flow velocities, from additive-free $8 \mathrm{M} \mathrm{KOH}$ containing $0.1 \mathrm{M} \mathrm{ZnO.}$

According to Figs. 7 and 9, recommendation for $\mathrm{Zn}(\mathrm{II})$ in a $\mathrm{Zn}$-air flow battery using $\mathrm{KOH}$ electrolytes without additives could be found between the concentration limits of $0.5 \mathrm{M}$ to $0.2 \mathrm{M}$, for any set of parameters (current density, linear flow velocity, temperature) used within this work.

Therefore, the usable charge density of an additive-free $\mathrm{Zn}$-air flow battery electrolyte may be derived from the most advantageous $\mathrm{Zn}$ (II) concentration range of 0.2-0.5 M, which corresponds to $16 \mathrm{Ah} \cdot \mathrm{L}^{-1}$ for the later one. Although this is rather low compared to some secondary portable batteries it is within the range of other proposed stationary energy storage technologies [35].

\section{Conclusions}

It was found that, dendrite-free $\mathrm{Zn}$ electrodeposition from additive-free alkaline zincate solutions is possible in a practical concentration range. The electrodeposition in highly alkaline electrolytes produces predominant mossy or spongy zinc deposits. Spongy deposits showed poor adherence to the carbon substrate. Once detached, these deposits are sparingly soluble in the electrolyte. The deposition conditions favoring mossy zinc are higher zincate concentration, 
higher temperature and a surface which provides a high number of nucleation centers. Raising the current density promotes the formation of dendritic deposits. The highest Coulombic efficiencies of $80 \%-93 \%$ were found for $0.5 \mathrm{M} \mathrm{ZnO}$ in $8 \mathrm{M} \mathrm{KOH}$, at elevated temperatures of $50-70{ }^{\circ} \mathrm{C}$, current densities of up to $100 \mathrm{~mA} \cdot \mathrm{cm}^{-2}$ and linear electrolyte flow velocities higher than $6.7 \mathrm{~cm} \cdot \mathrm{s}^{-1}$. Although the electrolytes with $0.2 \mathrm{M} \mathrm{ZnO}$ gave filamentous mossy zinc deposits at all combinations of parameters, it was found that, zincate concentrations lower than $0.5 \mathrm{M}$ result in a decrease of Coulombic efficiency and further shedding can lead to a continuous fading of available capacity in the flow battery.

\section{Acknowledgments}

The authors would like to thank John Collins and Dr. David Hall from C-Tech Innovation Ltd. (Chester, England) for designing the test flow cell within the POWAIR project. We thank Dr. Jaroslaw Wosik (CEST GmbH) for help with the SEM measurements.

\section{References}

[1] Thaller, L. H. 1974. "Electrically Rechargeable Redox Flow Cells." Presented at the 9th Intersociety Energy Conversion Engineering Conference, San Francisco, USA.

[2] Pan, J. Q., Sun, Y. Z., Wan, P. Y., Wang, Z. H., and Liu, X. G. 2005. "Halogen a High-Capacity Cathode for Rechargeable Alkaline Batteries." Chemical Communications 26 (July): 3340-2.

[3] Rychcik, M., and Skyllas-Kazacos, M. 1988. "Characteristics of a New All-Vanadium Redox Flow Battery.” Journal of Power Sources 22 (1): 59-67.

[4] Oriji, G., Katayama, Y., and Miura, T. 2004. "Investigation on $\mathrm{V}(\mathrm{IV}) / \mathrm{V}(\mathrm{V})$ species in a Vanadium Redox Flow Battery." Electrochimica Acta 49 (19): 3091-5.

[5] Kong, C., Wu, S., Sun, Y., and Li, K. 2011. "Vanadium Redox Battery System and Its Energy Storage Application in Wind Farm." Advanced Materials Research 282-283 (July): 112-5.

[6] Skyllas-Kazacos, M., Kazacos, G., Poon, G., and Verseema, H. 2010. "Recent Advances with UNSW Vanadium-Based Redox Flow Batteries." International Journal of Energy Research 34 (2): 182-9.

[7] Weber, A. Z., Mench, M. M., Meyers, J. P., Ross, P. N.,
Gostick, J. T., and Liu, Q. 2011. "Redox Flow Batteries: A Review." Journal of Applied Electrochemistry 41 (10): 1137-64.

[8] Yamamura, T., Shiokawa, Y., Yamana, H., and Moriyama, H. 2002. "Electrochemical Investigation of Uranium ß-Diketonates for All-Uranium Redox Flow Battery." Electrochimica Acta 48 (1): 43-50.

[9] Shiokawa Y., Yamamura, T., and Shirasaki, K. 2006. "Energy Efficiency of an Uranium Redox Flow Battery Evaluated by the Butler-Volmer Equation." Journal of the Physical Society of Japan 75 (Suppl): 137-42.

[10] Lloyd, D., Vainikka, T., Murtomäki, L., Kontturi, K., and Ahlberg, E. 2011. "The Kinetics of the $\mathrm{Cu} 2+/ \mathrm{Cu}+$ Redox Couple in Deep Eutectic Solvents." Electrochemica Acta 56 (14): 4942-8.

[11] Kim, H. S. 2011. "Electrochemical Properties of Graphite-Based Electrodes for Redox-Flow Batteries." Bulletin of the Korean Chemical Society 32 (2): 571-5.

[12] Wang, W., Luo, Q., Li, B., Wei, X., Li, L., and Yang, Z. 2013. "Recent Progress in Redox Flow Battery Research and Development." Advanced Functional Materials 23 (8): 970-86.

[13] Lee, D. U., Choi, J. Y., Feng, K., Park, H. W., and Chen, Z. 2014. "Advanced Extremly Durable 3D Bifunctional Air Electrodes for Rechargeable Zinc-Air Batteries." Advanced Energy Materials 4 (6): 1301389.

[14] Wang, K., Pei, P., Ma, Z., Xu, H., Li, P., and Wang, X. 2014. "Morphology Control of Zinc Regeneration for Zinc-Air Fuel Cell and Battery." Journal of Power Sources 271 (December): 65.

[15] Chamoun, M., Hertzberg, B. J., Gupta, T., Davies, D., Bhadra, S., Tassell, B. V., Erdonmez, C., and Steingart, D. A. 2015. "Hyper-Dendritic Nanoporous Zinc Foam Anodes." NPG Asia Materials 7 (April): e178.

[16] Cheng, F., and Chen, J. 2012. "Metal-Air Batteries: From Oxygen Reduction Electrochemistry to Cathode Catalists." Chemical Society Reviews 41 (6): 2172-92.

[17] Zhang, X. G. 2009. Encyclopedia of Electrochemical Power Sources. edited by Juergen, J., Dyer, C., Moseley, P., Ogumi, Z., Rand, D., and Scrosati, B. Amsterdam: Elsevier, 454-68.

[18] Sharifi, B., Mojtahedi, M., Goodarzi, M., and Vahdati Khaki, J. 2009. "Effect of Alkaline Electrolysis Conditions on Current Efficiency and Morphology of Zinc Powder." Hydrometallurgy 99 (1-2):72-6.

[19] Wang, R. Y., Kirk, D. W., and Zhang, G. X. 2006. "Effects of Deposition Conditions on the Morphology of Zinc Deposits from Alkaline Zincate Solutions." Journal of the Electrochemical Society 153 (5): C357-C364.

[20] Linden, D., and Reddy, T. B. 2002. Handbook of Batteries. New York: McGraw-Hill.

[21] Zhang, X. G. 1996. Corrosion and Electrochemistry of 
ZINC. New York and London: Plenum Press.

[22] Shaigan, N., Qu, W., and Takeda, T. 2010. "Morphology Control of Electrodeposited Zinc from Alkaline Zincate Solutions for Rechargeable Zinc Air Batteries." ECS Transactions 28 (32): 35-44.

[23] Zhang, L., Cheng, J., Yang, Y., Wen, Y., Wang, X., and Cao, G. 2008. "Study of Zinc Electrodes for Single Flow Zinc/Nickel Battery Application." Journal of Power Sources 179 (1): 381-7.

[24] Lee, C. W., Sathiyanarayanan, K., Eom, S. W., Kim, H. S., and Yun, M. S. 2006. "Novel Electrochemical Behaviour of Zinc Anodes in Zinc/Air Batteries in the Presence of Additives." Journal of Power Sources 159 (2): 1474-7.

[25] Lee, C. W., Sathiyanarayanan, K., Eom, S. W., Kim, H. S., and Yun, M. S. 2006. "Effect of Additives on the Electrochemical Behaviour of Zinc Anodes for Zinc/Air Fuel Cells." Journal of Power Sources 160 (1): 161-4.

[26] Wen, Y., Cheng, L., Zhang, L., Yan, X., and Yang, Y. 2009. "The Inhibition of the Spongy Electrocrystallization of Zinc from Doped Flowing Alkaline Zincate Solutions." Journal of Power Sources 193 (2): 890-4.

[27] Lan, C. J., Lee, C. Y., and Chin, T. S. 2007. "Tetra-Alkyl Ammonium Hydroxides as Inhibitors of $\mathrm{Zn}$ Dendrite in Zn-Based Secondary Batteries." Electrochimica Acta 52 (17): 5407-16.

[28] Iacovangelo, C. D., and Will, F. G. 1985. "Parametric Study of Zinc Deposition on Porous Carbon in a Flowing
Electrolyte Cell." Journal of the Electrochemical Society 132 (4): 851-7.

[29] Ito, Y., Nyce, M., Plivelich, R., Klein, M., Steingart, D., and Banerjee, S. 2011. "Zinc Morphology in Zinc-Nickel Flow Assisted Batteries and Impact on Performance." Journal of Power Sources 196 (4): 2340-5.

[30] Ito, Y., Wei, X., Desai, D., Steingart, D., and Banerjee, S. 2012. "An Indicator of Zinc Morphology Transition in the Flowing Alkaline Electrolyte.” Journal of Power Sources 211 (August): 119-28.

[31] Pei, P., Wang, K., and Ma, Z. 2014. "Technologies for Extending Zinc-Air Battery's Cyclelife: A Review." Applied Energy 128 (September): 315-24.

[32] Bockris, J. O'M., Reddy, A. K. N., and Gamboa-Aldeco, M. E. 2000. Modern Electrochemistry 2A: Fundamentals of Electrodics. New York: Kluwer Academic/Plenum Press.

[33] Gabe, D. R., and Robinson, D. J. 1972. "Mass Transfer in a Rotating Cylinder Cell-I. Laminar Flow." Electrochimica Acta 17 (6): 1121-7.

[34] Schmidt, V. M. 2003. Elektrochemische Verfahrenstechnik. Weinheim: Wiley-VCH.

[35] Leung, P., Li, X., Ponce de León, C., Berlouis, L., Low, C. T. J., and Walsh, F. C. 2012. "Progress in Redox Flow Batteries, Remaining Challenges and Their Applications in Energy Storage." RSC Advances 2 (27): 10125-56. 